\title{
A Competitive Study on the Interior Environment and the Interior Circulation Design of Malaysian Museums and Elderly Satisfaction
}

\author{
Raed M. A. Elottol (Corresponding author) \\ School of Housing, Building and Planning, University Science Malaysia.USM \\ Penang, Malaysia \\ Tel: 60-17-440-5868Ｅ-mail: aaraed@yahoo.com
}

Azizi Bahauddin

School of Housing, Building and Planning, University Science Malaysia.USM

Penang, Malaysia

Tel: 60-12-421-9109 E-mail: azizigt@gmail.com

Received: February 9, 2011

Accepted: March 9, 2011

doi:10.5539/jsd.v4n3p223

\begin{abstract}
The study explains how the interior environment, the circulation design quality, and visitors' satisfaction are related in the context of interior environment and design of museums in Malaysia. The research intends to examine the interior circulation design that interacts with the interior environment and space planning in museums. This is to understand the relationship between the elderly visitors' satisfaction and the interior circulation design. This paper plans to answer critical questions about the definition of the interior circulation design, and how the interior circulation design can relate to the elderly visitors' satisfaction in museums. Also to explore the relationship between elderly visitors' expectation, design quality and elderly satisfaction. This study is one of the few studies focus on elderly people within museums. The empirical analysis carried out on 509 of elderly visitors in 21 museums in Peninsular Malaysia allows us to confirm that the quality of interior circulation design and interior environment is a direct determinant of elderly satisfaction in museums. The results also reveal that there is a significant relationship between satisfaction and pre-expectation of interior environment. Finally, the interior environment elements of museums such as lighting design, furniture arrangement and finishes materials are also studied.
\end{abstract}

Keywords: Interior Environment, Museums' Design, Interior Circulation, Elderly, Satisfaction

\section{Introduction}

The purpose of this research is to investigate the elderly visitors' satisfaction in museums in Peninsular Malaysia. This study is one of the few studies focus on elderly people environment and circulation design. This research helps to find the relationship between elderly visitors' satisfaction and interior circulations design in museums. So the participants in the study are only the elderly visitors of the museums in Peninsular Malaysia. It becomes a fact the museums are the treasure-houses of the human race. They store the memories of the world's peoples, their cultures, their dreams and their hopes. Union of Great Britain Museum (1989), UGBM defines the museum as "an institution which collects, documents, preserves, exhibits and interprets material evidence and associated information for public benefit". Therefore the success of any museum is only in achieving the objectives of its formation. So the suitable museum is defined by the ability and success as shown by the activities carried out by independent objective functions and lines (UNESCO and Organisation 1973; Beirne 2003; UK Museum Association 2008; U.S. Department of Education and Institute of Education Sciences 2009; UK Standard 2010). Recently museums are not only a place to display or store collections, but museums have become cultural centres and place for education. More and more, museums' interior design are seen as the prologue to the museum experience that extends beyond the galleries into restaurants, shops, theatres, conference rooms, scientific centre, school and research area (Black 2005). So it becomes a fact that, the main central issue of the design of the multi-functional museum is the space planning and how the spaces and halls are connected, and its interior circulation. Because of that, the critical element of museum design is its interior circulation plan which gives form and shape to the building and at the same time differentiates between spaces according to the functions. Therefore interior designers must be careful and to consider a proper hierarchy of halls and spaces that 
balance aesthetic image with functional needs of elderly visitors (Black 2005; Ambrose and Paine 2006).This research addresses one particular component of the interior design of museums: its interior circulation.

Visitors' satisfaction in museums is a very difficult mission to achieve. Yalowitz (2002b) in his study highlights that visitors today have different expectations than those before 100 years. He states that an increased focus on entertainment requires interior design that is dynamic and draws visitors' attention. As a result, if visitors' attention and time are directed in ways that meet or exceed their expectations, they should leave feeling of satisfaction. Recently the satisfaction of the visitors becomes the key issue and one of the most important outcome variables for visitor institutions (i.e., whether or not visitors are satisfied with their experiences). For example consumer literature links satisfaction to repeated purchases, but in museums, satisfaction leads to positive word-of-mouth, which also leads to increased visitation. In general visitor's satisfaction has been discussed widely in many articles (Boulding, Kalra et al. 1993; Bordass 1996; Oliver 1996; Brock 2007; Black 2008; Bolton 2010; Brock University Team 2010). And with all these discussions and researches, until now there is no clear agreement about the determinant variables that affect the visitors satisfaction (Rojas and Camarero 2007). Several researches and studies (Babin and Griffin 1998; Baker and Crompton 2000; Balk, Zohreh et al. 2003; Babin, Lee et al. 2005; Babin, Lee et al. 2005; Banning and Schoen 2007; Baker 2008; Ballantyne, Packer et al. 2008) concentrated on describing satisfaction by the evaluation of perceived quality (confirmation/disconfirmation theories) from their expectations (Rojas and Camarero 2007). This method also used in this research to measure the satisfaction of elderly visitors, as until this moment there are no researchers studied or focused on the elderly visitors of the Malaysian museums. In addition, there are no clear statistics or measurements about the elderly satisfaction in Malaysia. In this context, researchers find the possible positive or negative effects, and related problems to ensure the satisfaction of the elderly visitors. It is believed that the desired outcomes should be of assistance to designers and the others who are considering better ways for museums building design, especially in Malaysia.

\section{Museums' Industry in Malaysia}

According to Hasan (2006) the actual museum industry in Malaysia began in 19th century. Therefore, the first museum opened in 1883 by the British in Taiping, Perak and that was before the Malaysia Day. The other one is the national museum which also was known as Selangor museum and was established in 1907. Hasan (2006) states in his study that the national museum is one of the prides of the nation. The national museum which has three storied structure and complicated decorated for exterior elevations representing the various motifs in Malaysia's diverse culture. The national museum, is also called Muzium Negara, is still a part of the government institution, under the ministry of culture, arts and heritage Malaysia (Rahah Haji Hasan 2006).

Taha (2008) figures out that the main function for all museums in Malaysia is to defend the national uniqueness and heritage. In addition, it is simply to instruct the public about it. According to Taha (2008), in Malaysia there are thirteen states and each state has its own museums that expose the local material, culture and heritage. In Malaysia, the ministry of culture, arts and heritage of Malaysia and the department of museums, Malaysia is the only authority that support the national history, cultural heritage (Rahah Haji Hasan 2006; Taha 2008). Furthermore, there are also over 50 museums in Malaysia that are managed by the federal and state governments. It is very important to know that through the years some museums in Malaysia have contributed extremely to the success of the tourism industry in the country, locally and internationally. The national museum, the rice museum and Islamic art museum are good examples of that support and contribution. The focus of these museums has exceeded beyond the museum walls and this brings about the implementation of a different kind of museum experience (Rahah Haji Hasan 2006; Taha 2008). With all previous advantages, the museum industries in Malaysia still face yet main and hard challenge in how to strengthen national unity with all the multi-cultural and multi-racial society of Malaysia. Thus in Malaysia, to build a state uniqueness is critical issue, in ensuring that the stability of country and harmony are not in danger. And this the reason that the Malaysian government exposes a big effort to inject millions of dollars into the museums industry (Taha 2008).

In additions to all above, museums in Malaysia still face many challenges such as; being a non-profit institution and a high maintenance body, museums must also ensure that they add value and contribute to the society in defending their existence. Malaysia needs to make museums relevant by organizing outreach programs and force to serve the educational purpose and source for students. Therefore, Malaysia government still considers museum as a semi academic and educational institution. Thus, the strength of a museum depends on its role in education progress (Rahah Haji Hasan 2006; Taha 2008). Towards to this efforts, during the first visit of minister of culture, arts and heritage, Datuk Seri Utama Dr Rais Yatim to the national museum in 2003, he asked museums' managers to think freely (out of the box) and to move away from the classic way of museum design and its exhibitions. He stated that Malaysia still needs a comprehensive enhancement to be conducted in 
museums in the areas of exhibition concept and design, displays, lighting and the use of interactive technologies to attract its visitors. The minister also assured that the local museums in Malaysia had not done a hard work to take full advantage of its potentials and asked for new changes which included injecting inspiration and innovations in exhibition design. He hopes to see museums in Malaysia play a more important role in learning, showcasing the nation's culture and history to visitors (Taha 2008). One of the major envelopment in museums' industry in Malaysia is that museums in Malaysia have integrated their programs within the school's curriculum. Therefore students are brought to museums to see, participate and enjoy museums' activities. Today one of the challenges of museum industry in Malaysia is to further develop relevant skills and human resource. In this regard, the ministry of culture, arts and heritage has enacted a law which was recently passed by the Parliament to establish a learning institution pertaining to arts and heritage, and museum studies to be part of the curriculum of the institution. Finally it can be concluded that museum bill performs a fixed task to make sure that museums fulfil their functions according to proper set standards, together with the museum code and ethics (Rahah Haji Hasan 2006; Taha 2008).

\section{Museums' Elderly Visitors and Satisfaction}

Only few previous researches focused on the elderly visitors. According to Rogers' study (1998), most of the museums visitors ranged from $50-70$ ages (elderly). As a result of his study also, elderly visitors of museums have expectations concerning interior environment and design. The elderly evaluation of the interior circulation and environmental systems can be based on (a) personal characteristics such as nostalgia, (b) experiences, and (c) general levels of satisfaction with the museum itself and interior design. Rogers (1998) also states that in order to use museum resources in the most effective manner, museums need more studies to identify what factors to consider for the visitors satisfaction and interior circulation in museums. Throughout museum basics there is a strong emphasis on the relationship between the museum and the people whom it serves. Through researchers' investigation and sites visits (2009), one of the main problems highlighted in the museums in Malaysia is the absence of interior design strategy and suitable solutions for elderly visitors. In addition, it is seen that in the museums in Malaysia it is easy for elderly to get exhausted as elderly people may tire particularly quickly. This is why the suitability and the comfort level of interior design and circulation design for the elderly visitors must be considered (Balk, Zohreh et al. 2003). As many of the elderly visitors have impaired mobility, and some of them are in wheelchairs, but more simply walk slowly or painfully in museum. Some of the elderly visitors also use sticks or simply find stairs difficult, and they simply have poor eyesight, and for them it is important to design a proper interior environment and circulation which can meet their satisfaction. In the museums in Malaysia, the absence of the design strategy and difficulty for accessibility for elderly and disabled visitors have been recorded (Haq and Girotto 2003). To overcome this problem, in the year 2002, Malaysian government endorsed the Biwako Millennium Framework for Action (BMF). It proclaimed the extension of the Asian and Pacific Decade of disabled and elderly people, 1993-2002 (Meng 2009). It is noted that accessibility to built environment and interior circulation are some of the areas out of 7 priority policy where Biwako Millennium Framework for action wants to achieve. Therefore this policy reflects the consequence of implementing barrier-free in order to accommodate involvement of disabled people and elderly in the society. Thus the good intention of the government and policy can be achieved if researchers prepare the desired guidelines of museums in Malaysia to be used by interior designers and developers. At the same time, Meng (2009) states in his study that the design strategy for interior environment, circulation design and accessibility for elderly and disabled in Museums' buildings in Malaysia needs to be ascertained (Meng 2009). Mohamed and Mustafa (2005) find that designers are often unfamiliar with the needs of the elderly visitors and users, as the need for user tests and demos is of greater importance. And until now there is no source or study that can give a great source of information related to the elderly needs, capabilities, and abilities (Mohamed and Mustafa 2005). However, holding these sessions is a real challenge for several reasons, as these challenges involve adjusting for diversity of the elderly population and their physical and cognitive differences (Black 2008). Therefore, based on the department of statistics in Malaysia $(2003 ; 2009)$ it becomes a fact that the demand for care and services for the elderly is clearly being recognized and effective implementation of policies is becoming crucial (Department of Statistics in Malaysia 2009). It is because of population projections, as the number of elderly people in Malaysia is likely to more than double to 3.4 million in the next twenty years (Department of Statistics in Malaysia 2009). An overview of the age-structure of the population for the past four censuses between 1970-2000 reveals a significantly decreasing proportion of population in the younger ages and a corresponding increase in the older age groups, indicating a continuing ageing trend in the coming years (Department of Statistics in Malaysia 2009).

Designers have to consider the elderly satisfaction, as currently, it becomes a fact that the elderly visitors are 
very interested to visit museums. In a study for a botanical garden museum, Hood and Roberts (1994) found that the group with the largest attendance was aged 55 and older (elderly). This group accounted for one-third to one-half of the visitors on any given day. Elderly visitors are more interested in purchasing in the gift shop, organized outings, and bringing out-of-town guests to the gardens. Another reason for designers to consider elderly visitors' satisfaction is their huge contribution in the society. Based on the local statistics in Malaysia, elderly people have a huge contribution to make economically and socially to the Malaysia (Department of Statistics in Malaysia 2009). Rogers (1998) in his study investigated the age of the museums visitors. He found that there are differences between the visits and ages, as the most questionnaires were filled by 60-70 year old people, and there were more people aged between 70 and 80 in the same museum (Rogers 1998). Wallace and Devita (2000) also investigated the age of the museums visitors. They found again that the most of the museums' visitors were under age category (50 -80) (Wallace and DeVita 2000).

\section{Interior Circulation Design}

Hsu (2004) recommends in his research that, in order to design museums properly interior circulation design must be considered, in addition to the solutions for interior movement in space/time in a sustainable plan. Although Hsu highlights a very important issue that the museums' visitors may not be conscious of how their bodies and movement are in a conversation and contact with the building and interior environment itself. Therefore the interior circulation design in the building is how we experience the three dimensionality of a building through the movement of our bodies with full consideration of time, sequence and space (Hsu 2004). Few researchers only defined the interior circulation. Black (2005) in his study defines interior circulation in the buildings as:

"They are all walking areas on all floors of a building required for physical access to some subdivision of space, whether physically bounded by partitions or not. Including Horizontal and Vertical circulation, which should be but is not limited to, public corridors, exhibition spaces, entrance foyers, elevator lobbies, tunnels, bridges, and each floor's footprint of elevator shafts, escalators and stairways. Also included are corridors, whether walled or not, provided they are within the outside facelines of the buildings to the extent of the roof drop line" (Black 2005).

Beirne (2003) also highlights and defines the horizontal circulation as: "All walking areas on all floors of a building required for physical access to some space including the features like corridors, lobbies, verandas, porches, doors, entrance foyers, and balconies". He also defines vertical circulation as; "All walking areas and mechanical tools installed in all floors of a building required for vertical physical access to some space including staircases, ramps, elevators and escalators" (Beirne 2003). Finally Stephen (2009) defines clearly the interior circulation in the buildings as:

"A term describes how visitors make their way through the facility. What pathways do they take? Do visitors circulate the way the designers intended? Do visitors miss key exhibits because of the architectural design of the facility? Which direction do visitors turn when they reach choice points? Do visitors have a circulation strategy (e.g., "Turn right and follow the perimeter") or do they simply wander more or less aimlessly?" (Stephen, 2009).

It becomes a fact that museums can be more successful if designers apply and implement the principles of circulation to the design process, and visitors will be more satisfied when the building is properly designed and when visitors are oriented properly to an exhibition area. Therefore, visitors tend to be more satisfied when the exhibition is designed with full consideration of the factors that determine circulation actions (Bitgood and Cota 1995). Thinking about circulation and interior environment should be started during the museums design process rather than added after the design is finished. In addition to that, the circulations factors and considerations should be an important part of the museum design and be an important part of the plan, launching with the planning stage and continuing through design. Therefore, circulation devices and elements should be defined by visitors and adjusted according to the visitors' input and not exclusively by designers who may not be able to predict the impact of these elements on visitors (Griggs, 1983). It becomes a fact that the efficiency of interior circulation system in the museums determined by the basic shape and form of building itself. So buildings of the same internal floor area and same function differ in the proportion of space absorbed by the elements of interior circulation and in the design style of circulation elements such as lifts, corridors and other mechanical equipment. Researchers stated that the time needed by a visitor to move from one area within the building to another area and the enjoyment of doing this by visitors are affected by the building form and circulation style that is designed (Söderlund and Vilgon 1999; Springer-Heinze, Hartwich et al. 2003; Stephanie Clark Ridgway, Livingston et al. 2005; Sharma and Dhariya 2006; Shettel 2010). 
The design of interior circulation elements such as stairs, corridors and mechanical circulation elements are very important issues for interior designers. In addition to that, the quality of the building depends at first on the basic analysis of the interior circulation elements and traffic flow of visitors. For example the main entrance area is considered small but it is carrying a major quantity of traffic of visitors. It becomes principal node of a circulation pathway, with the optimum shape of the building dependent on the ratio between internal traffic and movement to and from the outside. Therefore, the elements of circulation in museums such as lifts and escalators, stairs and corridors differ in visitors' carrying capacity and their spatial and design requirements. (figure1) This is why the interior designers must consider and match the characteristics of each element with those of the traffic generated in buildings (Bitgood and Thompson 1993; Bitgood 1999; Bitgood 2005).

According to S. Bitgood (2010) there are two main types of interior circulation. They are horizontal circulation and vertical circulation. Horizontal path way describes how visitors make their way through the facility within the same floor using circulation elements. It is simply all walking areas on all floors of a building required for physical access to some space including the features like corridors, lobbies, verandas, porches, doors, entrance foyers, and balconies. Vertical circulation describes how visitors make their way in the building between different floors and levels using circulation elements. It is simply all walking areas and mechanical tools installed in all floors of a building required for vertical physical access to some spaces including staircases, ramps, elevators and escalators, (Figure 2) (Bitgood 2010). Vertical and horizontal circulations are considered as part of the form of the circulation space that affects generally the visitors' movement within museums, (Figure 3). The location of the corridors, staircases and its design, width and slope have to be considered within the overall design steps because they affect the visitor's perception of space and level of visor's satisfaction (Bitgood 2010). All elements of interior circulation are important in the museum since it is the key to decisions regarding how the collection will be displayed and viewed. More practically, circulation is critical for moving the visitors through the building (Bitgood 2010). S. Bitgood (1992) in his research highlights some of the principles of the interior circulation design and interior environment. Generally he divides the principles into three main areas: conceptual orientation, visitors' circulation, and way finding. Bitgood also coined the term of " positive word-of-mouth" for the visitors' satisfaction about interior environment and pathway design.

\section{Aspects of Interior Circulation Design}

Bitgood (2009) highlights that there are three main aspects of circulation to museums' visitors. They are conceptual orientation, wayfinding, and circulation. He describes that conceptual orientation includes consciousness and understanding of the circulation elements and arrangement of the facilities. In his study, he also explains how visitors' expectations and prior experiences play a key role in conceptual orientation. He considers expectation and experience as the most important factors affect on-site circulation and orientation systems. Bitgood also describes wayfinding as "topographical" or "locational" orientation, which describing how visitors are able to find places in museums. Bitgood states that "orientation devices such as maps and direction signs are critical for wayfinding." (2010). Kaynar (2010) points out that, designer must meet the circulation function in the building, and the architectural design should embrace appropriate space to house and to improve traffic from area to area (Kaynar 2010). According to Hsu (2004), this includes at least five aspects: approach, entrance, configuration of the path, path/space relationship and form of the circulation space (Figure 6). Ching (2004) describes clearly the relationship between spaces, pathway design and people. Since people move in time through a sequence of spaces, the circulation pathway can be considered as links between spaces within building. He highlights that "this is why people experience the space in relation to where they have been and where they anticipate going" (2004).

\section{Research Hypotheses}

According to Gronroos (2000), design quality can be defined from two perspectives. They are technical quality (what is delivered to the visitors) and the functional service quality (how it is delivered) (Rojas and Camarero 2007; Pile 2010). In another study, Brady and Cronin (2001) figure out that the design quality can be outlined by three perspectives. They are outcome quality, interaction quality, and physical environment quality in buildings. As environment quality refers to the ambient conditions (Rojas and Camarero 2007). Oliver (1997) states that visitors' interpretation is related to the level of expectations. Therefore, according to (Rojas and Camarero 2007) expectations is known as previous predictions or beliefs of visitors before they enter the building. Based on Rojas \& Camarero (2007) expectations are shaped by several sources of factors and information such as, communication, advertising, word of mouth referrals, or experiences. Even for the visitors without experience they still have their own expectation about the design (Rojas and Camarero 2007). According to Oliver (1997), the quality of design is based on perceptions of excellence. Oliver (1997) also states that it is logical to believe that perceived quality is influenced by the expectations of the visitors (Rojas and Camarero 2007). It becomes a 
fact that visitors use their expectations to evaluate design quality and performance. Therefore, researchers propose the first hypothesis:

(H1. Visitors' expectations positively influence visitors' perception of interior design quality and interior environment of Museums).

Recently, design quality is believed to be the right judgment exposed by visitors who estimating the quality level of design. So, satisfaction and design quality are highly interrelated (Rojas and Camarero 2007). Researchers accept the theory said that quality leads to satisfaction. Olsen (2002) approved with evidence that visitors' satisfaction is preceded by perceived quality (Rojas and Camarero 2007). Also, in the field of museums and visitors' satisfaction, there are studies that agreed that design quality happens prior to visitors' satisfaction (Rojas and Camarero 2007). On this basis, we propose the second hypothesis:

(H2. Interior circulation design (overall) of Museums positively influences elderly visitors' satisfaction.)

Disconfirmation happens when interior circulation design is lower or higher than what visitors expected after they made the final decisions (Oliver 1996). The visitors create negative or positive implications for the experience of service or design and its evaluation (Rojas and Camarero 2007). If the interior designs higher or lower that the visitors' expectations, a positive or negative disconfirmation occurs and this will increase or decrease the level of satisfaction. According to Oliver (1996) "consumer satisfaction is a function of expectations and disconfirmation, and prior expectations are used as the comparable standard. Past empirical research has shown that expectations have a significant effect on disconfirmation"(Oliver 1996; Rojas and Camarero 2007).

\section{Methodology}

In order to test the proposed hypotheses, the empirical study performed is based on information collected by means of a questionnaire presented to visitors of 21 selected museums in Malaysia. The 21 museums are located in Kuala Lumpur, Terengganu, Selangor and Kedah in Malaysia. After proceeding to the quantitative study of 21 museums, some interviews and observations (qualitative study) conducted for four selected museums. Interviews with the museums' managers, employees and visitors were performed in order to know visitors' reactions and emotions during their visits. A questionnaire was developed to test the aforementioned hypotheses. The questionnaire was divided into two parts. The first part covered the experience, mood and the expectations before the visit. The second part referred to the design quality, the disconfirmation of expectations, the pleasure and the satisfaction after the visit. A preliminary draft of the questionnaire was developed and administered to some visitors. The first survey was conducted during the months of July to October 2009 and the total number of questionnaires collected was 509. A second set of data was collected through observations and interviews during October, and November 2009, providing valid data for analysis. Those surveyed were asked to answer the first part of the questionnaire, (i.e. the questions referring to their experience, mood and expectations). After answering these questions, the visitor held onto the questionnaire during the visit, and the second part of the questionnaire was completed upon exit. Questionnaires were collected upon visitors' exit. Of these 800 questionnaires, 613 were returned. One hundred and four questionnaires were excluded (40 incomplete and 64 the age of participants were under 65 years old). All elderly visitors above 65 were chosen to answer the questionnaire for every museum. Table 1 below shows the distribution of the respondents, the zones' and the number of questionnaires in the survey.

The total numbers of questionnaires analysed were 509 questionnaires with observed response rate of $76.6 \%$. Analysis was conducted using the statistical software package SPSS version 17.0 with a sample size of $509, \alpha$ (the probability of making a correct retention is 0.95$)=0.05$, $\mathrm{df}($ degree of freedom) $=1.0$.

Of the 509 respondents, 290 were men (57.4\%) and 215 were women (42.6\%). Three hundred and forty eight visitors $(69.3 \%)$ were $65-70$ years old, One hundred and forty eight visitors $(29.7 \%)$ were equal or more 71 to 90 years old. Of the 509 respondents, $271(53.9 \%)$ were locals, and $229(45.5 \%)$ foreigners. Of the locals, 162 were Malay (32.2\%), 61 were Chinese (12.1\%), 76 were Indian (15.1\%). Indicating that Malay visitors are more interesting to visit museums than others. Of the 509 Participants, only 43 (8.5\%) of elderly visitors came alone to the museum, while $212(42.1 \%)$ came with friends and $185(36.7 \%)$ came with their families. The rest of participants $60(11.9 \%)$ visited museums with organizations. The scale of expectations was constructed of five items adapted from the scale proposed by (Rojas and Camarero 2007) and also applied to the case of museums and exhibition centres. The scale of perceived quality (six items) was prepared from the proposal of Brady and Cronin (2001). All of the included items of expectations were adapted to reflect the context of interior circulation in museums. The results of the responses (either agree or disagree) were presented under the check-list of three factors; a) horizontal circulation design b) vertical circulation design, and c) interior environment. 
In the horizontal circulation item, the results of the responses (either agree or disagree) were presented under the check-list of six factors based on the component analysis such as; horizontal accessibility, halls' arrangement and spaces, corridors and entrance lobbies, waiting areas, orientation system, furniture arrangement and interior layout. In the vertical circulation design, the results of the responses (either agree or disagree) were presented under the check-list of three factors based on the component analysis such as; vertical accessibility, position, visibility and capacity of lifts, ramps and staircases, and interior paths and circulation. In the interior environment item, the results of the responses (either agree or disagree) were presented under the check-list of four factors based on the component FA analysis such as; creativity and interior environment, interior materials and textures, interior lights and interior colours. Table 1 below shows the result of factors analysis for each category. To measure satisfaction (five items) the Oliver (1996) scale was used and included additional items that measured the intention to repeat the visit and word-of-mouth recommendation. All scales were validated the values of reliability were calculated by the Cronbach alpha in each case.

\section{Analysis and Results}

The first hypothesis (H1) stated that there will be no significant relationship between elderly visitors' expectation in the museums, and the perception of the design quality. The correlation coefficient is -.083-**. As the result in the next table 2 suggests, a significant negative relationship does not exist ( $\mathrm{Sig}=0.061)$; therefore, this can be concluded from these result, that elderly visitors' expectation before they entering the museum don't determine or affect the elderly visitors' perception of the design quality of the interior circulation in museums.

The second hypothesis (H2) stated that there will be a significant relationship between elderly visitors' satisfaction in the museums and interior circulation design quality. As shown in table 2, the correlation coefficient is $0.685^{* *}$. Sig (2-tailed) or P value is $0.000 \leq \alpha 0.05$ which can be concluded from these result that there is a positive significant relationship between elderly visitors' satisfaction in the museums and interior circulation design, thus $\mathrm{H} 2$ is confirmed that the interior circulation design of the museums affect the level of the elderly satisfaction. Results also stated that there will be a positive significant relationship between elderly visitors' satisfaction, and time spent in museums. The correlation coefficient is $0.404^{* *}$. As the result, a significant relationship exists; therefore, this can be concluded from these result, that time spent in the museum was influenced by elderly visitors' satisfaction, thus time spent in museums consider as a good an indicator of satisfaction. In other words satisfied visitors tend to spend more time walking in the museum. Looking at all the scores in the data presented in below as a whole, it is overwhelmingly clear that in all of the factors under all the different categories, the respondents have until today a far greater negative perception towards interior circulation design of museums in Malaysia. Such negatively weak perception of the circulation design towards museums in Malaysia is an expression of their dissatisfaction level in the nature of the circulation designs and interior environment of these museums. For the overall findings, the section presents the summary of the overall composite averages as in Table 3. Finally, in the three categories, the respondents have scored $41.03 \%<50 \%$ for qualitative and $43.26 \%<50 \%$ for quantitative analysis, suggesting a clear feeling of dissatisfaction towards the interior circulation design and the interior environments of the selected museums.

\section{Discussion and Conclusions}

This study began with the aim of analyzing a specific aspect of interior design applied to museum in Malaysia, and the formation of visitor satisfaction. The first implication of this research is the confirmation of hypotheses due to its high validity and explanatory power. In particular it is found that the respondents selected from the museums in Malaysia have a high level of expectation towards the interior circulation design and interior environment in museums. Therefore, such positively strong expectation is undoubtedly an expression of their level of experience and trust towards the design industry in Malaysia. This study found that interior circulation design quality appears to be multidimensional consisting of different three dimensions. The Three dimensions are horizontal circulation design, vertical circulation design, and interior environment design of museums. Under each dimension there are many different components, as under horizontal dimension there are seven factors such as, horizontal accessibility, halls' arrangement and spaces, corridors and entrance lobbies, waiting areas, orientation system, furniture arrangement and interior layout. At the same time, under vertical dimension there are six components such as vertical accessibility, position, visibility and capacity of lifts, ramps and staircases, and Interior paths and circulation. While under interior environment dimension there are four components such as, creativity and interior environment, interior materials and textures, interior lights and interior colours. The scores from the survey have demonstrated overwhelmingly same low perceptions and bad expression about the interior circulation design and interior environment of museums in Malaysia. These negative design qualities of the circulation design in the museums together with the positive and high expectations of the elderly visitors compositely justify the low level of general satisfaction of the elderly visitors in the selected museums. The 
interesting finding was the idea that interior circulation designs that must be good, as a high percentage of the elderly visitors find it useful and can enhance their satisfaction level. Yet, little thought seems to have been given to what interior environment and circulation are, what is necessary to achieve visitors' circulation efficiency, and what benefits can be expected. From site investigations and empirical studies done in this research, it is found that interior designers of museums in Malaysia have not considered effectively the circulation design of elderly visitors and their needs. In sum, museum design is likely to be more successful if principles of interior circulation design are applied to the design process. Therefore, elderly visitors learn more and are to be more satisfied when they are properly circulated and oriented to an exhibition and when the exhibition is designed with an understanding of their needs and abilities. This will require us to re-think again about the interior environment and the circulation design quality of museums in Malaysia. So interior circulation design could be the trend in museums and visitors' studies in the future, and more studies of this nature should be carried out. However, the interior designers are invited to continue this initial investigation of interior circulation design quality and interior environment in museums, especially in new areas of design where we knew our elderly preferences, needs and abilities. Interior environment and circulation elements are the design strategy, a success value and quality indicator of the museums' design. It is the communication and circulation tools, and technology that permit the combination of all museums' services and visitors.

\section{References}

Books

Ambrose, T. and C. Paine (2006). Museum Basics. New York, Routledge Taylor \& Francies Group.

Black, G. (2005). Engaging Museum ( Developing Museums for Visitors Involvement). New York, Routledge.

Ching, F. D. K. (2004). Architecture: Form. Space \& Order. New York, Van Nostrand Reinhold Company.

Oliver (1996). A Behavioral Perspective on the Consumer. Boston, Mass., Irwin- Me Graw-Hill.

Pile, J. F. (2010). Interior Design London Sage Inc.

UNESCO and E. Organisation (1973). Museums, Imagination and Education Switzerland, Sage Publications, Inc.

\section{Articles}

Babin, B. J. and M. Griffin. (1998). "The Nature An Updated of Satisfaction: Examination and Analysis." Journal of Business Research 41(1): 127-136.

Babin, B. J., Y.-K. Lee, et al. (2005). "Modeling consumer satisfaction and word-of-mouth: restaurant patronage in Korea." Journal of Services Marketing 19(3): 133-139.

Babin, B. J., Y.-K. Lee, et al. (2005). "Modeling consumer satisfaction and word-of-mouth: restaurant patronage in Korea." Journal of Services Marketing 19(3 ): 133-139.

Baker, D. A. and J. L. Crompton. (2000). "Quality, Satisfaction And Behavioral Intentions." Annals of Tourism Research 27(3): 785-804.

Baker, M. B. (2008). "Service: Satisfaction And Value." Business Travel News 47(12): 23-25.

Balk, A. v. G., L. W. Zohreh, et al. (2003). "Satisfaction among Museum Visitors: The Holistic Approach Confirmed Empirical Evidence from the Anne Frank House visitors." Economic and Social Institute, Free University Amsterdam 3(2): 101-118.

Ballantyne, R., J. Packer, et al. (2008). "Environmental awareness, interests and motives of botanic gardens visitors: Implications for interpretive practice." Tourism Management 29 (1): 439-444.

Banning, S. A. and M. Schoen. (2007). "Maximizing public relations with the organization-public relationship scale: Measuring a public's perception of an art museum." Public Relations Review 33 (1): 437-439.

Bitgood, S. (2010). "An Analysis of Visitor Circulation: Movement Patterns and the General Value Princip." Jacksonville State University 16(8): 256-264.

Bitgood, S. and D. Thompson (1993). "Multicultural Pluralism and Visitor Evaluation." VISITOR BEHAVIOR 6(2): 3-4.

Bitgood, S. C. (1999). "Impact of setting factors on visitors." VISITOR STUDIES Volume II(Issue 2). 
Bitgood, S. C. (2005). "Visitor Circulation: Is There Really A Right-Turn Bias?" Journal of visitor Behavior Volume X(Number 1): 5-11.

Black, J. (2008). "Museum Application Design for Older User."

Bolton, S. (2010). "The Task Force on Museums and First Peoples, a Decade Later: A Case Study of the McCord Museum of Canadian History." 22-32.

Bordass, B. (1996). "Museum Collections in Industrial Buildings A selection and adaptation guide." Museums and Galleries Commission 22(1): 9-38.

Boulding, W., Kalra, et al. (1993). "A Dynamic Process of Service Quality: From Expectations to Behavioral Intentions." Journal of Marketing Research vol. 30, no. 1, February, pp 7-27.

Brock (2007). Pedestrian Circulation. Brock University Campus Plan, Brock University.

Brock University Team. (2010). "Pedestrian Circulation: Brock University Campus Plan." 7(2): 9-14.

Haq, S. and S. Girotto. (2003). "Ability and Intelligibility: Way finding and Environmental Cognition in the Designed Environment." International Space Syntax Symposium 4(2): 68-87.

Kaynar, I. (2010). "Visibility, movement paths and preferences in open plan museums: An observational and descriptive study of the Ann Arbor Hands-on Museum." University of Michigan, USA 13(2): 189-202.

Mohamed, B. and R. A. Mustafa. (2005). "Heritage Tourism In A Multicultural Society: The Case Of Malaysia."

Rojas, C. d. and C. Camarero. (2007). "Visitors' experience, mood and satisfaction in a heritage context: evidence from an interpretation center." Tourism Management 29 (3): 525-537.

Sharma, K. and T. D. Dhariya. (2006). "Towards an inclusive, barrier free and right based society." empowerpoor 2(4): 1-16.

Shettel, H. (2010). "Some Things to Think About." Journal of Visitor Studies Association Vol. II(1): 132-138.

Söderlund, M. and M. Vilgon. (1999). "Customer Satisfaction and Links to Customer Profitability: An Empirical Examination of the Association Between Attitudes and Behavior." SSE/EFI Working Paper Series in Business Administration No. 1999:1 2(1): 211-232.

Springer-Heinze, A., F. Hartwich, et al. (2003). "Impact pathway analysis: an approach to strengthening the impact orientation of agricultural research." Agricultural Systems 78(1): 267-285.

Stephanie Clark Ridgway, M. Livingston, et al. (2005). "Visitor Behavior In Zoo Exhibits With Underwater Viewing." Visitor Studies Journal.

UK Standard. (2010). "Access For All." Design note 2: Internal circulation 3(8): 31-34.

\section{Conferences}

Rahah Haji Hasan. (2006). Management practices in two of the oldest museums in Malaysia. INTERCOM Confrence Malaysia.

Wallace, L. and M. C. DeVita. (2000). Service to People: Challenges and Rewards, Reader's Digest Fund. International conference UKN.

\section{Reports}

Beirne, S. (2003). Suzie Beirne m.d.i.a, Usenature: http://www.usenature.com.

Department of Statistics in Malaysia (2009). Socio-Economic Characteristics Of The Elderly In Malaysia.

Rogers, M. L. (1998). An exploration of factors affecting customer satisfaction with selected history museum stores. . Graduate Faculty. Texas Texas Tech University.: 158.

Taha, D. D. A. H. (2008). Museums In Malaysia: Challenges And Development. Kuala Lumpur, Department of Museums, Malaysia.

\section{Websites}

Meng. (2009). Built Heritage vs Accessibility. Retrieved 09-02-2009: http://www.pmh83.blogspot.com/ 
U.S. Department of Education, I. o. E. S. (2009). manual describes standard practices for initiating, conducting, reporting, and maintaining a postsecondary institutional facilities inventory. Retrieved 29-09-2009, from http://nces.ed.gov/pubs2006/ficm/toc.asp

UK Museum Association. (2008). What is a museum? , from http://www.museumsassociation.org/faq

Table 1. The Distributions of the Questionnaires

\begin{tabular}{|l|l|l|c|}
\hline No. & Museum Name & State & $\begin{array}{l}\text { Number of } \\
\text { Questionnaires }\end{array}$ \\
\hline 1 & Pucuk Rebung Royal Gallery Museum & Kuala Lumpur & 40 \\
\hline 2 & Telekom Museum & Kuala Lumpur & 35 \\
\hline 3 & Textile Museum & Kuala Lumpur & 30 \\
\hline 4 & Asian Art Museum & Kuala Lumpur & 40 \\
\hline 5 & Malay Ethnographic Museum & Kuala Lumpur & 30 \\
\hline 6 & Islamic Arts Museum & Kuala Lumpur & 48 \\
\hline 7 & Maybank Numismatic Museum & Kuala Lumpur & 39 \\
\hline 8 & National Handicraft Museum & Rawang & 30 \\
\hline 9 & Orang Asli Museum & Gompak & 30 \\
\hline 10 & FRIM Museum & Kepong & 30 \\
\hline 11 & Royal Malaysian Air force Museum & Kuala Lumpur & 30 \\
\hline 12 & Architecture Museum & Melaka & 30 \\
\hline 13 & Melaka Sultanate Palace Museum & Melaka & 30 \\
\hline 14 & State Museum & Shah Alam & 50 \\
\hline 15 & Padi Museum & Kedah & 30 \\
\hline 16 & Terengganu State Museum & Terengganu & 30 \\
\hline 17 & Maritime Museum & Melaka & 30 \\
\hline 18 & National Art Gallery & Kuala Lumpur & 40 \\
\hline 19 & Archaeological Museum & Kedah & 30 \\
\hline 20 & Ibrahim Hussein Museum and Cultural Foundation & Langkawi & 28 \\
\hline 21 & National Museum & Kuala Lumpur & 120 \\
\hline TOTAL & Peninsular Malaysia & All Zones & $\underline{\mathbf{0 0 0}}$ \\
\hline Number of Questionnaires Distributed & & $\mathbf{8 0 0}$ \\
\hline Collected Back & & $\mathbf{6 1 3}$ \\
\hline Excluded & & $\mathbf{1 0 4}$ \\
\hline Response Rate & $\mathbf{7 6 . 6 \%}$ \\
\hline Questionnaires Used for Analysis & $\underline{\mathbf{0 9 9}}$ \\
\hline
\end{tabular}

Table 2. Correlation between Expectation, Satisfaction and Circulation Design Quality

\begin{tabular}{|l|l|l|}
\hline & Overall Expectation. & $\begin{array}{l}\text { Overall Circulation Design } \\
\text { Quality. }\end{array}$ \\
\cline { 1 - 1 } Overall Expectation. & 1 & \\
\hline Sig. Value & & 1 \\
\hline Overall Circulation design quality. & $\mathbf{- . 0 8 3 -}$ & \\
\hline Sig. Value & $\underline{\mathbf{. 0 6 1}}$ & $\underline{\mathbf{. 6 8 5}}$ \\
\hline Overall elderly visitors' Satisfaction. & $\mathbf{- . 4 9 5 - * *}$ & $\mathbf{. 0 0 0}$ \\
\hline Sig. Value & $\underline{\mathbf{. 0 0 0}}$ & \\
\hline
\end{tabular}

**. Correlation is significant at the 0.01 level (2-tailed).

*. Correlation is significant at the 0.05 level (2-tailed) 
Table 3. Overall Composite Averages (Satisfaction scores) of all Categories

\begin{tabular}{|l|l|l|}
\hline \multirow{2}{*}{ Categories of factors } & \multicolumn{2}{|l|}{ Selected Museums } \\
\cline { 2 - 3 } & $\begin{array}{l}\text { "Satisfactory" scores from } \\
\text { Qualitative survey (yes) }\end{array}$ & $\begin{array}{l}\text { "Satisfactory" scores from } \\
\text { Quantitative survey }\end{array}$ \\
\hline Vertical circulation design & $\underline{\mathbf{4 2 . 3 3} \%}$ & $\underline{\mathbf{4 4 . 3 3} \%}$ \\
\hline Horizontal circulation design & $\underline{\mathbf{4 1 . 1 2} \%}$ & $\underline{\mathbf{4 4 . 1 2} \%}$ \\
\hline Interior environment & $\underline{\mathbf{3 9 . 6 6} \%}$ & $\underline{\mathbf{4 1 . 3 3} \%}$ \\
\hline Overall composite average & $\underline{\mathbf{4 1 . 0 3} \%}$ & $\underline{\mathbf{4 3 . 2 6} \%}$ \\
\hline
\end{tabular}

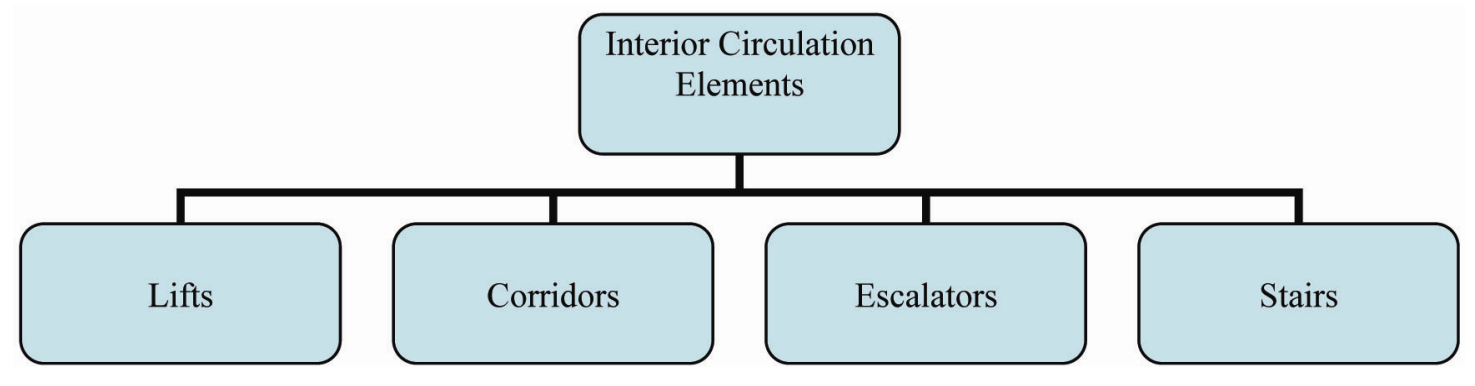

Figure 1. Elements of Interior circulation design

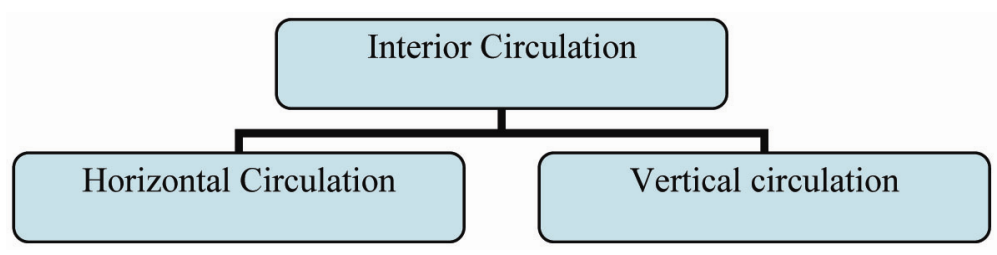

Figure 2. Types of Interior Circulation

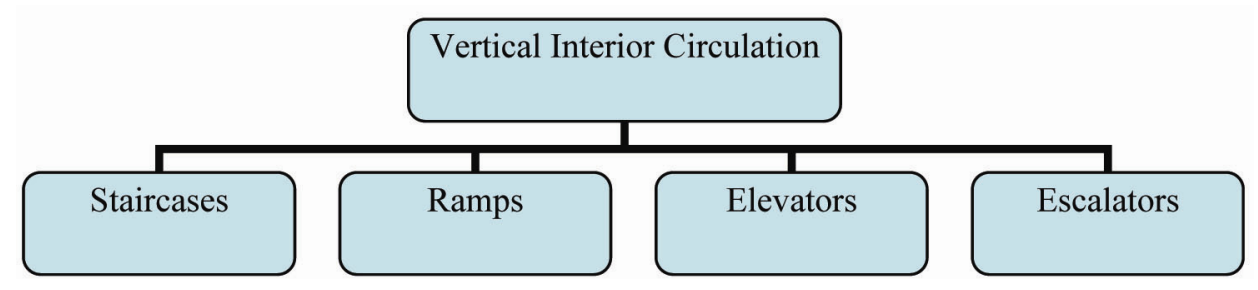

Figure 3. Design Elements of Interior Vertical Circulation System

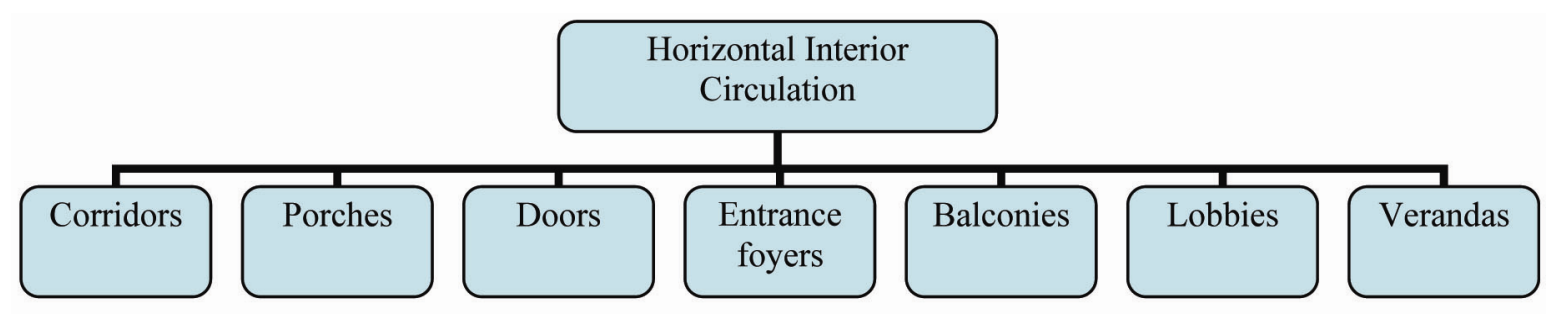

Figure 4. Design Elements under Horizontal Interior Circulation System 


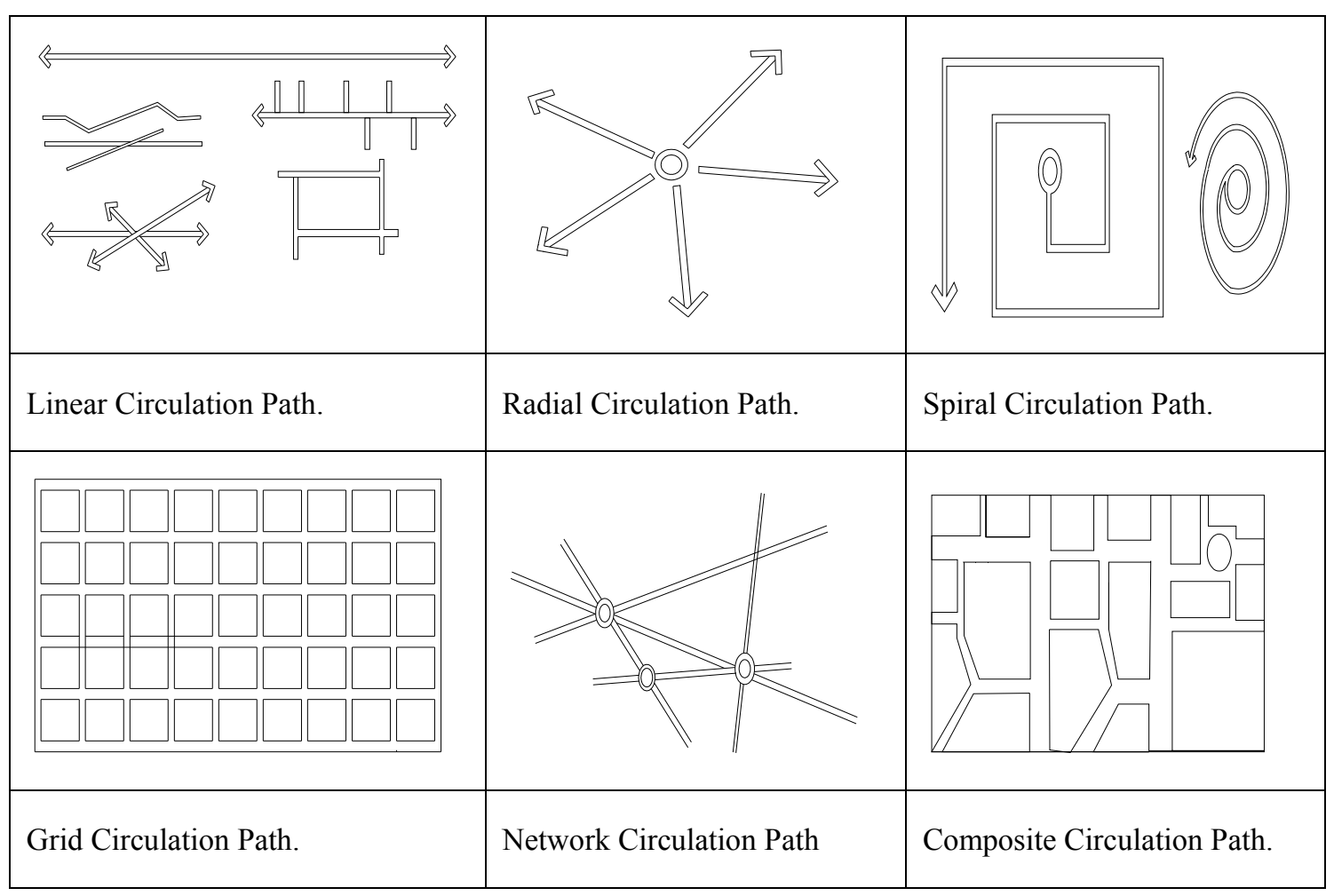

Figure 5. Types of circulation paths within buildings (Ching 2004)

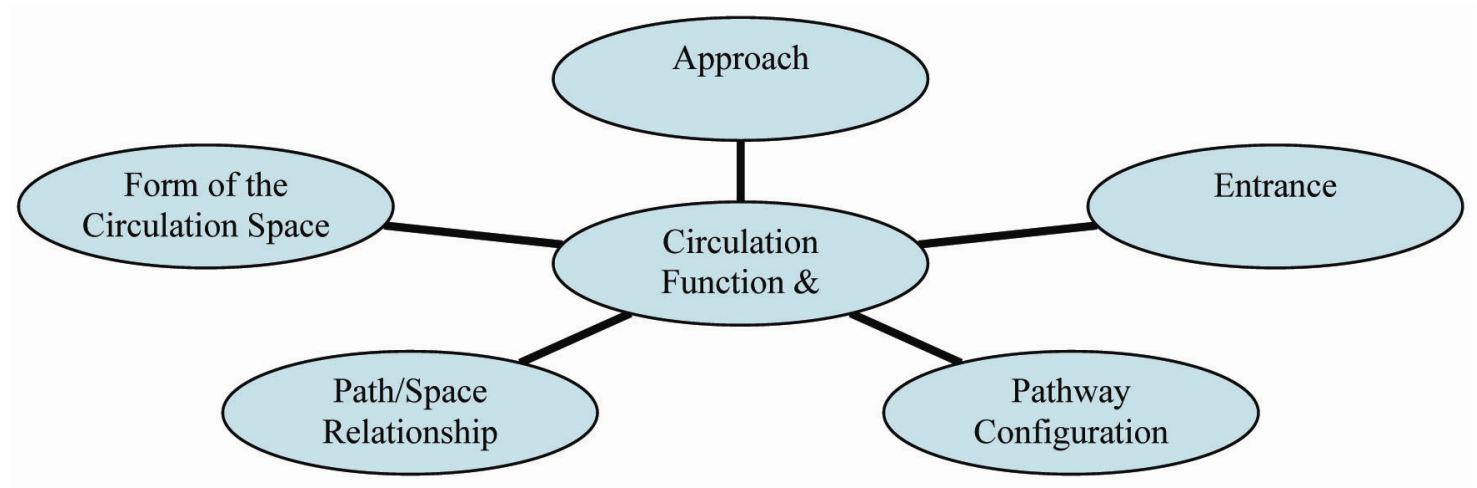

Figure 6. Components of circulation function \& design within museums 